\title{
Social Beliefs for the Realization of the Speech Acts of Apology among Jordanian EFL Graduate Students
}

\author{
Ala'Eddin Abdullah Ahmed Banikalef ${ }^{1} \&$ Marlyna Maros $^{1}$ \\ ${ }^{1}$ School of Linguistics and Language Studies (SOLLS), Faculty of Social Sciences and Humanities, Universiti \\ Kebangsaan Malaysia, Malaysia \\ Correspondence: Ala'Eddin Abdullah Ahmed Banikalef, School of Linguistics and Language Studies (SOLLS), \\ Faculty of Social Sciences and Humanities, Universiti Kebangsaan Malaysia, Malaysia. E-mail: alaukm@yahoo.com \\ Received: May 3, 2013 \\ Accepted: May 30, 2013 \\ Online Published: May 31, 2013 \\ doi:10.5430/elr.v2n1p134 \\ URL: http://dx.doi.org/10.5430/elr.v2n1p134
}

\begin{abstract}
This study is an investigation into the apology strategies adopted by Jordanian EFL (English as a Foreign Language) graduate students in various situational settings. The objective of this study is to highlight the influence of social status and social distance on the choice of apology strategies. Data were collected through Discourse Completion Tasks (DCT) and semi structured interviews. Briefly, the findings revealed that most the students used Illocutionary Force Indicating Device (IFID) and accept responsibility strategies. Other new strategies (arrogance and ignorance, blame something else, swearing) which fall outside the model adopted from Cohen \& Olshtain also appeared in the subjects' responses. The newly detected strategies are culture-specific acts that are deeply rooted in the Jordanian society. The findings also showed that the choice of the apology strategy is affected by social status more than social distance.
\end{abstract}

Keywords: Apology Speech act, Communicative competence, EFL learners, Apology Strategies

\section{Introduction}

Since communicative competence achieves superiority in the goals of foreign and second language pedagogy, a better understanding of how second-language socialization takes place is essential. Consequently, the change from grammatical to communicative competence in language learning has notably enhanced that need. It has become explicitly obvious that separating the teaching of second language words and phrases from their sociocultural situation may result in misunderstanding which may hamper interaction purposes (Blum-Kulka, 1991). Although speech acts are a universal concept, and are embedded in all languages, their usage varies from one culture to another(Al-Issa, 2003; Hussein \& Hammouri, 1998). Cross-cultural studies of speech acts have revealed that L2 learners face problems in applying speech acts when they interact with native speakers of the target language (Chen, 1993; Cohen \& Olshtain, 1983). However, teaching speech acts as an aspect of communication skills is not highlighted in Jordanian English institutes, high schools and universities. For this reason Jordanian (EFL) learners often fail to recognize the correct function of speech acts in EFL (Al-Issa, 2003; Bataineh, 2006).

Among communicative functions, apologies present a complicated interaction for language learners, who have to restore the "breached harmony" (Hussein \& Hammouri, 1998, p. 66) between themselves and their interlocutors after the inflicted offense, actual or potential. In other words, apologies might be problematic for EFL/ESL learners due to numerous reasons, for instance, the impacts of transfer from native language to L2 based on the sociocultural choices and sociolinguistic forms in performing speech acts. Researchers such as Eslami-Rasekh and Mardani (2010)have found thatIranian EFL learners tend to use their own language norms in expressing the speech actin the target language. Intercultural miscommunication happens when there is a breakdown in communication between interlocutors of two different cultures or languages due to sociolinguistic transfer (Al-Issa, 2003). Hence the purpose of this study, that is, to investigate the communicative pattern of the Jordanian students studying in Malaysia because as there is a constant influx of them pursuing their studies in this country, so is the increased possibility for miscommunication to happen either with the locals or with other international students here. Consequently, communication breakdown can lead to serious negative misjudgments of the speaker's personality and his or her intention. Apology is chosen as an indicator of communicative competence among this group with respect to their use of English language for survival outside of their country. The choice of this speech act is due to its importance as a repair mechanism toward any potential misunderstanding or misinterpretation of utterances or messages. 
It was accepted that second language learners incline to transfer the sociolinguistic norms of their native language when communicating with native speaker of the target language and scholars in the area of speech act realization have attributed sociolinguistic transfer as the main factor of cross-cultural communication breakdown (Crystal, 2001; Wilson, Gosling, \& Graham, 2012). It is with these notions that the analyses of apology strategies in this study will be conducted; that is, to apply this notion in relation to sociolinguistic factorss pecifically social status and social distance, to the Jordanians who are using English as a foreign language.

This study will elucidate the needs reflected in the field of EFL teaching. First of all, it will contribute to a better understanding of the nature of communicative competence, particularly, the rules that govern the use of language. On the other hand, it will draw learners' attention to think of language as an integral part of culture. Finally, to the researcher's knowledge, up to now there has been no similar study in the Jordanian context concerning examining the sociopragmatic and pragmalinguistic variations in the expression and realization of speech acts of apology by EFL graduate learners.

A study of this scope of language use spotlights on the cultural differences that strike language users' attempts at expressing apologies in EFL. A person may apologize because culturally it is a polite ritual to do so and it usually differs from one society to another. For example, in some cultures, it is an offense to arrive late for a meeting and a person must apologize for that while in other cultures being late is not a major offense. As misinterpretations occur between people of different cultures and to avoid cross-cultural conflicts this study is carried out with great hope to bridge the gap in the area of producing the speech act of apology by Jordanian EFL learners. The current study can help policy makers of Malaysian universities offer courses in terms of how to engage between foreign students and the local community. It can also bring awareness to the Jordanian students of the cultural differences in producing apology.

\section{Literature review}

Research on speech acts is either focused on the culture-specificity of the item or on the contrastive nature of the forms from the native and nonnative languages. Most researchers usually took a cross-cultural perspective, that is, one that contrasted the native language of the learners to English as a Foreign or as a Second Language. Studies on apologies carried on into the millennium. Although apology is a common part of our language of relationships, researchers have found few studies that present culturally significant differences in apologies between Jordanian speakers and other cultures. Most of the studies reviewed below have compared Jordanian Arabic apologies with American English apologies.

Hussein and Hammouri (1998) was the earliest published study that the researchers found which discussed the similarities and differences between the way Americans and Jordanian apologized.They collected their data via DCT that contained 18 items and each situation requires the use of a form of apology. The DCT was first designed in English for the Americans, then translated into Arabic language and administered to 50 Jordanian male students and 50 female students enrolled at Yarmouk University, Jordan. Their age ranged between 18 and 32 years old. The American sample consisted of 40 participants. Both the Jordanian and American responses were identified, categorized, and analyzed to discover the types and percentages of the apology strategies used. Hussein and Hammouri concluded that the strategies of Jordanian speakers were more varied than that of the Americans. The Jordanian participants employed 12 strategies, while the Americans, seven. Among the significant findings regarding social power, responses from Jordanian respondentsshowed that whenever the recipient was higher in rank, the apology strategies included honorific addresses.

Later on Bataineh (2008) conducted another comparative study between the Jordanian Arabic and American English speakers and shed light on the cultural differences that affect language users' attempts at expressing themselves. She studied responses of two randomly chosen groups of one hundred American and one hundred Jordanian students and collected data by the means of DCT. Bataineh has used two tests; one of them was taken from Sugimoto (Chomsky, 2006) who compared the strategies used in apology by American and Japanese students, while the other test was designed by Bataineh herself. She found differences between the two cultures in expressing apology; and that lie in the fact that Jordanians used more (1) statement of remorse, (2) strategy of promising not to repeat the offense, (3) invoking Allah's (God's) name, and (4) the use of proverbs. On the other hand, Americans used more compensation, and tended to blame others as well as themselves when trying to apologize for the committed offense.

Another comparative study of Jordanian Arabic was by Al Adaileh (2007) who conducted an investigation of the realisation patterns of apologies in British English and Jordanian Arabic, with special attention to politeness phenomena in Jordanian culture as contrasted with British culture. He employed the theoretical framework of the model of politeness by Brown \& Levinson (1998) in which a difference is made between two main constituents of 
face, namely, negative face and positive face. He also used the open-type questionnaire and interviews to collect data. His findings showed that Jordanian subjects were not inclined to use IFIDs as frequently as did the British subjects. In addition, participants of both languages were likely to employ the expression of regret subcategory. He also proposed that the using of the substrategy such as "I am afraid + sentences" was used only by British subjects, so that it could be assumed that this substrategy (I am afraid + sentences) is a language-specific strategy. This means that each language has its own conventional expressions to realize its IFIDs. According to him, the most frequent IFID expressions in the responses of Jordanian Arabic are as the following: asif, muta'assif, asef (sorry), verbs: atta'assaf (sorry), a 'tather (apologise), samehni (forgive me), and nouns: 'afwan (pardon), alma'thirah, and al'uther (apology). Noteworthy, both British participants and Jordanians leaned to employ the most commonly used remedial expressions, specifically "I'm sorry," and the interchangeably used asif/mut'assif. He concluded that apology is strongly affected by social parameters.

Similarly, Al-Sobh (2013) aimed in his study to investigate the apology strategies Arabic native speakers used in different situations. The sample made up of eight Jordanian English as Foreign Language (EFL) undergraduate students at Irbid National University. Discourse completion test (DCT) was used to generate data related to the apology strategies used by each participant. Six varied apology situations designed to elicit apologies in varied situations were administered to the subjects. The findings revealed that the apology strategies used were apology and regret, explanation, offer of repair, equal - equal, low high and responsibility. The researcher concluded that the participants didn't use clear apology strategies in the given situations because they might not study them in school textbooks adequately.

It is assumed that second language learners incline to transfer the sociolinguistic norms of their native language when communicating with native speaker of the target language, scholars in the area of speech act realization attributed pragmatic transfer as the main factor of cross-cultural communication breakdown (Pütz \& Neff-van Aertselaer, 2008; Trosborg, 1994). According to Ellis (1997), pragmatic transfer refers to the phenomenon of transferring and applying speaker's L1 pragmatic knowledge in L2 situations. In this line also Cohen and Olshtain (1983) refers to pragmatic transfer as a learner's strategy of incorporating native- language based elements in the target language production.

In the field of pragmatic transfer, Lee (1999) conducted a significant study to find out patterns of second language use and the conditions that affect pragmatic language behaviour through analyzing apology-complaint adjacency pairs among Korean second language learners of English. The subjects were 170 Korean learners of English in the US, 47 Korean learners of English in Korea, 52 English native speakers, and 46 Korean native speakers. The participants produced the adjacency pairs through DCT, which consisted of seven complaint-apology scenarios that varied by the contextual factors of power status and social distance. The findings showed that even Koreans and Americans shared the same range of complaint and apology communicative strategies; however, they were different in how parameters such as power relation and social distance determined their choices of using particular strategies.Pragmatic transferfrom their first language has been noticed in their responses. The findings also revealed that the target-like pragmatic competence can be promoted through more practice and interaction with other English speakers. To sum up, Lee claims that linguistics and pragmatic competence are knowledge and skills that go hand in hand and cannot be studied separately from each another.

A more recent study by Thijittang (2010) investigated the speech act of apology in Thai and English and examined the pragmatic strategies of English used by Thai undergraduate university students. The data were gathered and analyzed quantitatively via DCT elicitation and qualitatively via interview. DCT questionnaires were gathered from 160 Thai undergraduate students of different disciplines at a university in Thailand, whereas the participation for interview involved nine students. The Questionnaire contained 15 different situations according to various sociolinguistic factors. The collected data were analyzed based on the four main strategies classified by Holmes (1990). The findings showed that English has more strategies for apologizing than Thai language. Thijittang concluded that the sociolinguistic factors (social status, social distance, and severity of offence) have a momentous influence on the production of apologies.

In the area of cross-cultural study of speech acts, linguists have focused on how a particular act of speech is linguistically realized in different languages.Moreover, most of previous studies in Jordanian context are comparative works between Jordanian native Arabic speakers and English native speakers (Hussein \&Hammouri 1998; Bataineh 2004; Al Adaileh 2009), and these studies paid little or noattention to the impact of pragmatic transfer on the EFL learners. Pragmatics, as a matter of fact, has typically been ignored by textbooks and teacher training programs, particularly in Jordan, and despite the abundant empirical studies on speech acts in general; few data-based studies have focused on L1 transfer of apology expressions. The current study, therefore, sheds light on 
the Jordanian graduate EFL learners' comprehension and production of speech act of apology in an English language environment.

\section{Methods}

This section includes a description of the methodology of study used by the researchers in order to investigate the use of the speech act of apology used by Jordanian EFL graduate students. It also gives a description of the society and the sample of the study. The tool used in collecting data is also identified briefly.

\subsection{Instrumentations}

The data were elicited through discourse completion tests (DCTs) and semistructured interviews. Eight verbal discourse completion tests (DCT) adopted from Al Adaileh (2007) distributed to Jordanian participants.These situations were selected because they represent contexts with controlling factors that are essential in the study, and they are suitable in the Jordanian cultural context. As aforementioned, the situations in DCT were selected to be classified by the social distance and social status. Accordingly, social status here refers to the social power of the interlocutors by the way of their institutionalized role in society; for instance, the manager at work will have more power than an employee. In the DCT, the speakers in these situations, such as university professors (situation 1), fathers (5), and customers (situation 7) are in a higher status than the hearers. On the other hand, the speakers of these situations, such as, the students (situation 2), employees (situation 3) are in lower status than the speaker. The social status of the other situations is assumed to be equal as in stranger interlocutors (situation 6), friends (situation 4), and coworkers (situation 8).

Social distance was used to describe familiarity between the interlocutors, whether they were close friends, strangers, or acquaintances. Close friends, a speaker and a friend (situation 4), work colleagues, speaker, and coworkers (situation 8), and father and son (situation 5) have been considered as people who know each other well (close social distance). An employee and boss (situation 3), professor and student, (situation $(1,2)$ were taken as people who know each other, but not well (neutral social distance), and strangers or unfamiliar people as a car driver (situation 6) and a customer and a waiter (situation7) have been considered as people who do not know each other well or unfamiliar people (distant social distance).

A combination of methods was used to reduce the limitation and disadvantage of using the questionnaire in this study. The purpose of using interview is justified by the need to have full-picture about the participants' perceptions as to whether their predictions of apology are influenced or not by the social variables. The interviews were based on 3 questions adopted from Thijittang (2010). Question items were selected based on the purposes of the study, which were connected to situations in the DCT. The following are the interview questions:

1) Do you translate apology from Jordanian Arabic to English when you perform apology act in English? Why?

2) Do you vary apology patterns to match hearers' social status that are higher, equal or lower status? Why?

3) Do you vary apology patterns to match hearers' social distance that are close, neutral, or far social distance? Why?

\subsection{Sample}

Since the major purpose for this study regards the investigation of pragmatic strategies of Jordanian students who study English and reach the advanced level at least, it is necessary to have postgraduate students as a cohort for studying. By postgraduate participants, the researcher can probe the nexus between pragmatic competence and overall language proficiency.

The sample of the current study consists of 40 male postgraduate Jordanian students. Their ages range between 25-40 years old. The participants had studied English as a Foreign Language in their home county for at least twelve years and most of them came to Malaysia to follow up their higher education in majoring English language. Therefore, the majority are living in Malaysia for at least one year where English is the primary medium of communication. Female participants were excluded because there is no female EFL postgraduate Jordanian student studying in Malaysia at the time of data collection for the current study.

\subsection{Procedures}

All participants received the questionnaire via e-mail. This was because most of them lived in scattered and distant areas, making it hard for them to participate in the interviews if it were to be conducted face-to-face. This technique is done by sending DCTs via email, as an attachment, to the participants who also sent in their electronically, as an attachment (Mustaffa et al., 2011). An introduction of the purpose of the questionnaire was included in the email 
message. It should be noted here that the researcher met all the participants via Skype (internet telephone) and explained the purpose of the questionnaire, then asked them to answer the questionnaire in the meantime. Although the interview need was made known to the participants, only the first five volunteers were accepted to participate in it. All interviews are held in the linguistic lab of UKM. The length of the interviews is approximately 10 minutes were recorded then transcribed by the researchers themself.

\subsection{Data analysis}

Apology strategies collected were analyzed based on six super-strategies separated into substrategies as designed by Cohen and Olshtain $(1981,1983)$. To examine strategies easily, the researcher has assigned a code to each strategy. All strategies were coded from A1 to I. As with the intensifications of apology, following Olshtain and Cohen (1989), both cases of these intensifications have been tabulated as in their model.

The apology strategies and their codes are shown in Table 1:

Table 1. Apology Strategies and Their Codes

\begin{tabular}{ll}
\hline Code & Strategy \\
\hline A 1 & An offer of apology \\
A2 & An expression of regret \\
A3 & A request for forgiveness \\
B & Explanation or account \\
C1 & Explicit self-blame \\
C2 & Lack of intent \\
C3 & Expression of self-deficiency. \\
C4 & Expression of embarrassment \\
C5 & Self- dispraise. \\
C6 & Justifying the hearer. \\
C7.1 & Denial of responsibility, e.g., "It wasn't my fault.", \\
C.7.2 & Blame the hearer, e.g., "It's your own fault." \\
C.7.3 & Pretend to be offended, e.g., "I'm the one to be offended." \\
D & Concern for the hearer \\
E & Offer of repair. \\
F & Promise of forbearance. \\
\hline Code & Strategy \\
\hline EXM & External Modification \\
INTEN & Intensifiers \\
\hline New strategies \\
\hline G & Arrogance and ignorance \\
H & Blame something else \\
I & Swearing \\
\hline
\end{tabular}

\section{Findings and Discussions}

\subsection{Apology Strategies by Jordanian EFL Learners}

Findings from this study show that explicit expressions of apology, specifically, expressing regret, is the most frequently occurring strategy applied by Jordanian EFL participants (16.6\%). This finding corresponds with that of other studies (Alfattah, 2010; Bataineh, 2008), that apologies given are explicit. An offer of repair is the second most frequently used apology strategy (13.8\%), followed by an explanation or account strategy which occurs with a frequency of $9.7 \%$. The apologizer might feel that he or she needs to offer repair directly after apologizing to palliate his offense and to avoid any escalation of conflict with the other party. However, this study's findings demonstrate that no other strategies account for more than 7\%; other strategies like self-dispraise, denial of responsibility, and 
pretend to be offended are not detected in all EFL data. The acceptance of responsibility strategy is the second most used strategy accounting for $18.2 \%$, while denial of responsibility strategy accounts for only $2.1 \%$ of the total responses.

It should be noted here that an acceptance of responsibility which consists of another six sub-strategies $(\mathrm{C} 1, \mathrm{C} 2, \mathrm{C} 3$, $\mathrm{C} 4, \mathrm{C} 5$, and $\mathrm{C} 6$ ) is the second most used strategy accounting for $18.2 \%$, while denial of responsibility strategy (C7.1, C.7.2, C.7.3) accounts for only $2.1 \%$ of the total responses. Briefly, the most frequently used category was the Illocutionary Force Indicating Device, which was used in $21.2 \%$ of the responses, followed by accepting responsibility strategy (18.2), then offer repair strategy because it accounts for $13.8 \%$ of the total responses.

Although the production of speech act of apology can be found in all languages, the realization of this speech act varies according to the culture of the community(İstifçi, 2009). In lieu of the presupposition, the findings revealed new apology strategies in the Jordanian data which were not in the original model that was adopted from Cohen \& Olshtain $(1981,1983)$. As a result, these new strategies are considered as culturally specific manifestations that characterized the apologies in the Jordanian society. The new strategies are as follows:

The new strategies are as follows:

1) Arrogance and ignorance

This strategy is resorted to the speaker when he responded directly without any consideration for the hearer's face. The act of apologizing needs an utterance or action which aimed to 'set things right'. However, in some cases the speaker who has performed the offense may not find himself as guilty; hence did not feel the necessity to apologize at all, and, as a result, the speaker may deliberately damage hearer's face (degraded hearer's face). Briefly, this strategy, (arrogance and ignorance), is identified when the wrongdoer violated the hearer's face needs arrogantly and ignored his responsibility for the offence. The following are some examples of the new apology strategies from Jordanian EFL data:

- "change my order, I do not want it"

- "I did not finish reading it yet"

- "I think it is not big deal to change my order even I have ordered that, you have to bring me what I asked for now"

2) Blame something else

This strategy is an attempt to reduce the wrongdoer's responsibility for the act. Thus, when a wrongdoer used 'blaming' strategy he admitted to committing the offense but denied responsibility by placing blame on others. Examples are as follows:

- “.....I had headache...."

- ".....this dish is so oily....."

- “.....when I wanna see you, things go wrong with me..."

\section{3) Swearing}

One of the specific linguistic formula which is deeply rooted in the cultural and religious beliefs of the Jordanian participants detected in this study was the use of swear words. Swearing in Arabic context is a common routine feature that often takes place in the most types of speech acts (Al-Adaileh, 2007). According to Abdel-Jawad (2000), swearing is an act of adding a linguistic formula ( a form of speech) to what one says or does 'as' a solemn or formal appeal to God ( or to a deity or something held in reverence or regard) in witness to the truth of statement, or the binding character of a promise or undertaking ( p.217). Most of substrategies were used together with swear words. Swearing in Arabic context is a common routine feature that often takes place in the most types of speech acts (Al Adaileh 2007).

Briefly, swearing was used as a tool to intensify apology. Therefore, swearing is considered as significant device in the social life of Arabic context in general and Jordanian Arabic in particular. Thus, swearing has a genuine power to confirm truth among interlocutors. Although, Muslims are commanded to swear by god through saying "Wallah al adheem" ( Allah is the Great), in fact they may use other swear words such as, the family members -specially the dead, the life or honor of close relatives, or to swear by body parts such as the moustache, which is considered as a symbol of manhood (Abdel-Jawad, 2000). In order to be honest in apologizing, Jordanians inclined to prelude their apologies with swearing formula, consider the following examples:

- “...I swear I forgot it...."

- “.....By God, it was out of my hand." 
The results showed that the order of frequency where expressions of the new strategies occurred is as the following: arrogance and ignorance (5.2\%) was used frequently, in particular, in situations 7 and 8 , where the hearer is of a higher status than the speaker, followed by the expressions of blame something else (4.2\%). This means that the speaker shouldered responsibilities over his acts, but he tried to reduce the seriousness of the offence and at the same time tried to save his face. The expressions of swearing act occurred with a frequency of $4.1 \%$. Thus, swearing has a genuine power to confirm the truth among the Jordanian interlocutors. By swearing, the speaker made an effort to emphasize his or her apology and confirmed his/her honest intent to repair the social equilibrium.

\subsection{The effect of sociolinguistic factors}

\subsubsection{Social Status Affecting Apologies by Jordanian EFL Students}

Previous studies have indicated that social status is great influence on the realization of selecting apology strategies. Similarly, the analysis showed that apology strategies by EFL Jordanian speakers were also deeply influenced by the hearer social status factor. However, since in Jordan it is rare for communication to take place with native speakers of English, it is probable that Jordanian EFL learners transferred their native language norms to the English language, which may lead to communication breakdowns with native English speakers. Therefore, it is significant to highlight the way of apologizing in English by the Jordanian EFL learners according to different sociolinguistic factors between the conversationalists.

Findings showed a real interaction between apology strategy selection and the sociolinguistic factors. Figure 1 illustrates the distribution of apology strategies in the data according to the social status relationship between the participants. The analysis exposed that in lower status, Jordanian EFL speakers applied the highest proportion of the following strategies; 'express regret (A2, 14), expression of self-deficiency $(\mathrm{C} 3,17)$, offer of repair (E, 15), and repetition of the IFID $(\mathrm{K}, 4)$. On the contrary, in higher status, Jordanian EFL speakers record the highest proportion of using two strategies; explanation or account $(\mathrm{B}, 18)$, and arrogance and ignorance strategy $(\mathrm{G}, 5)$.

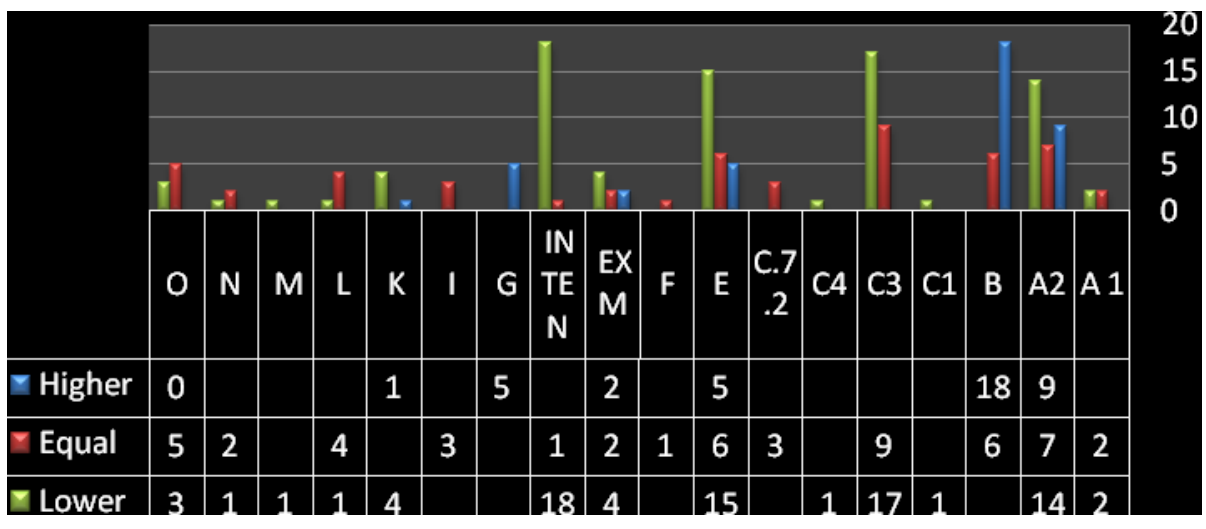

Figure 1. Frequency distribution of apology strategies interacting with a social status

The following examples from situation 1 (university professor not returning student's term paper) demonstrated the utterances without the explicit expression of apology.

- "I did not finish reading it yet"

- "It is okay. When I finish reading it I will inform you"

- "well, not bad, I will bring it later"

- "I don't read it yet"

In the above examples, Jordanian EFL learners did not apply the explicit expression of apology, which should consist of offer apology, expressions of regret, and a request for forgiveness, in the apology situation. As another evasive option, they applied the 'explanation or account', offering repair, and/or arrogance and ignorance strategy. This however could be understood as the speakers' conscious or unconscious awareness of their having a higher status and social distance from the hearer. Hence, it can be assumed that Jordanian EFL learners are sensible to their social status as university lecturers, as well as, to the hearer's social status as students. In fact, in the Jordanian culture apologizing to students may degrade their social status as lecturers, so they inclined to avoid direct (explicit) apology 
strategy. However, in case of equal status, Jordanian EFL speakers' apologies ranged from accepting responsibility and apologizing, to making excuses and blaming someone else. This means that apology among equal status speakers is more casual and lengthy. In other words, Jordanians usually don't find it necessary to say 'sorry', or to take responsibility for 'simple matters' like forgetting a meeting with a friend. See the following examples.

- "Oh man, why didn't you call me? You know that I always forget"

- "Take it easy, nothing happened, why did not remind me before?"

- "I want to apologize for you my dear, because I was so busy and couldn't come"

As expected, Jordanian EFL speakers in the lower status showed the highest proportion of using intensifiers as it occurred 18 times across situation 2. The following examples from situation 2 (student not returning professor's book) illustrated how Jordanian EFL speakers of lower status intensify their apology.

- "I'm very sorry my professor, I just forget the book at home. I'm really apologizing."

- "I am very sorry Prof. I really forgot all about it, I will bring it by tomorrow for sure, and I really apologize for that."

- "Oh, I am so sorry professor I forgot to bring the book with I promise I will bring it soon. I really appreciate if you forgive me Prof."

From this it can be assumed that the intensification of apology of Jordanians learners of English was heavily related to the social status factor. This result may be the outcome of cultural impact, where it is a common practice in Jordan where the people of higher status have more authority and therefore are given overt show of linguistic and behavioral appreciation and tokens of appreciation. In this case, the lecturers are clearly more senior and hence higher in status than the students, so the students would avoid making any offenses to them, instead would in their best way expressed reverence to the lecturers.

4.2.2 Apology strategies interacting with social distance

Another factor that greatly influenced the choice of apology strategies is social distance (Thijittang \& Lê, 2010). In this study, with respect to the social distance factor, the most frequently occurring apology strategy was an expression of offering repair (E, 28.0\%) and it was used frequently particularly by the speakers of distant social distance group. The second most frequent strategy used was the expression of regret (A2) found mainly from the speakers from distant (23.0\%) and neutral (21.0\%) social distance. This finding comes in line with that of Brown and Levinson (1987) that the more the social distance between the interlocutors, the more it requires the high presence of respect through apologies; while speakers from close social distance group had little inclination to direct apologizing. The results of this study indicated that the responses to apology speech act were applied most with neutral and unfamiliar groups, and used less with the close distance group.

With regard to the use of "intensifiers," Jordanian EFL speakers in the neutral distance group (18.0\%) used the highest proportion of the strategy than the other two groups. Again, this could be because of the impact of the hearer's social status since in the neutral distance group the hearer was higher status than the speaker. On the other hand, in the case of using external modifications, they were used only among speakers of the close social distance group and neutral close social distance group by $4.0 \%$ and $3.0 \%$, respectively.

\subsection{Students' Perception Regarding Expressing Apology in Forging Language}

The following part will present the participants' opinion regarding issues of translating apology from Jordanian Arabic to English when performing it in English, varying apology patterns to match hearers' social status that are higher, equal or lower status, and varying apology patterns to match hearers' social distance that are close, neutral or far social distance.

\subsubsection{Translating Jordanian apology into English apology}

All the participants said that they always translate apology from Arabic language into English. As a result, the new utterances in the target language have the same norms of the native language. This ambiguous translation can lead to a communication breakdown between Jordanian EFL learners and American native speakers. Some possible illustration of this phenomenon is the learners' lack of pragmatic development in the target language, learners' deficiency L2 linguistic knowledge, and inadequate sociocultural knowledge in L2. 


\subsubsection{Using different apology patterns to match a hearer's social status}

The Jordanian EFL participants' also varied their apology strategies to match the hearer's social status. They varied their apology strategies according to their perspective about the hearer's social status whether the hearer is of higher or of lower social status. As expected, when interviewed, all of them agreed that the social status of hearer is important in determining the patterns of utterances of speech act in their daily life communication.

4.3.3 Applying different apology strategies to match a hearer's social distance

All the participants agreed that apology strategies have to be varied according to the social distance between the interlocutors, as one of the participants put it as "more familiarity between interlocutors' needs utterances less formality."

Consequently, the result from the interview data affirms the result from the DCT data that while apologizing, Jordanian EFL learners are so influenced by the hearer's social status. This means that they are inclined to apologize to hearer of higher social status with a more formal pattern of utterances. Contrarily, when Jordanian EFL participants apologize to the hearer from a lower or equal social status, they are inclined to use simple pattern of apology, that is, "Sorry." This could be due to the influence of their L1 sociolinguistic norms in realizing speech acts in the target language (English). This is known as pragmatic transfer. This means that Jordanian EFL learners use Jordanian culture norms to apologize in English. To sum up, the patterns of apology strategies are determined by the influence of the social status factor.

\section{Conclusion}

It was detected from the interlanguage data that the Jordanian EFL learners were inclined to transfer their L1 (Arabic) pragmatic norms to L2 (English). For example, lecturers in Jordan are regarded higher in social status than students, so they most likely feel no need to offer any explicit apology to their students. For that reason, they prefer to use explanation apology strategy. Put differently, the common practice in Jordan is that people of superior status are supposed to be appreciated more and have more authority over their inferiors. As a result, Jordanian EFL learners transferred their L1 sociopragmatic knowledge into the target language (English). Furthermore, Jordanian EFL learners tended to transfer their pragmalinguistic knowledge to L2 (English). For instance, some Jordanian EFL learners tried to intensify their apology through repeating an expression of regret (e.g., sorry, sorry, sorry). This inappropriate form of intensification could be due to the lack of pragmalinguistic competence in using the proper intensifiers (e.g., sorry, very, so). In this line also, some Jordanian EFL learners attempted to intensify their apology through using swear words (Oh, I am so sorry. I swear I forgot it). Briefly, the performance of speech act of apology among Jordanian EFL learners is influenced by a number of factors such as

a) transfer of their $\mathrm{L} 1$ pragmatic competence,

b) transfer their L1 sociolinguistic knowledge,

c) learners' inadequacy of linguistic proficiency in L2, particularly in doing speech act,

d) learners' lack of knowledge in using L2 idiomatic expressions, especially in the field of speech act.

The findings of the current study have implied to pay more attention to improve learner's L2 sociolinguistic competence and pragmalinguistic knowledge of the target language. Moreover, this study shows the importance of developing EFL learners' competence in using L2 idiomatic expressions of speech acts in general and particularly in apologizing. EFL learners can improve their sociolinguistic competence and pragmalinguistic knowledge through observing the native speakers' use of speech acts in everyday communication (drama, movies). EFL teachers also must raise their students' awareness about the differences between student's native language and the target language regarding pragmatic knowledge. Therefore EFL teachers have to consider new teaching methods which reflect L2 pragmatic factors. It is recommended that further research be undertaken in the following areas:

- It might be interesting to examine the hearer's reaction whether s/he accepts the apology or not.

- Variables like gender, age and the rank of the imposition could be suggested to be investigated in the future research.

\section{References}

Abdel-Jawad, H.R.S. (2000). A Linguistic and Sociopragmatic and Cultural Study of Swearing in Arabic. Language Culture and Curriculum, 13(2), 217-240. http://dx.doi.org/10.1080/07908310008666600

Al-Adaileh, B.A.M. (2007). The speech act of apology: a linguistic exploration of politeness orientation in British and Jordanian culture. University of Leeds. 
Al-Issa, A. (2003). Sociocultural transfer in L2 speech behaviors: Evidence and motivating factors. International Journal of Intercultural Relations, 27(5), 581-601. http://dx.doi.org/10.1016/S0147-1767(03)00055-5

Al-Sobh, Mahmoud Ali. (2013). An Analysis of Apology as a Politeness Strategy Expressed by Jordanian University Students. International Journal of Humanities and Social Science 3(2), 150-154.

Alfattah, Mohammed Hasan Ahmed. (2010). Apology Strategies of Yemeni EFL University Students. MJAL (0974-8741), 223-379.

Bataineh, R.F. (2006). Apology strategies of Jordanian EFL university students. Journal of Pragmatics, 38(11), 1901-1927. http://dx.doi.org/10.1016/j.pragma.2005.11.004

Bataineh, R.F. (2008). A cross-cultural comparison of apologies by native speakers of American English and Jordanian Arabic. Journal of Pragmatics, 40(4), 792-821. http://dx.doi.org/10.1016/j.pragma.2008.01.003

Blum-Kulka, S. (1991). Interlanguage pragmatics: The case of requests. Foreign/second language pedagogy research, 255272.

Chen, R. (1993). Responding to compliments A contrastive study of politeness strategies between American English and Chinese speakers. Journal of Pragmatics, 20(1), 49-75. http://dx.doi.org/10.1016/0378-2166(93)90106-Y

Chomsky, N. (2006). Language and mind: Cambridge University Press. http://dx.doi.org/10.1017/CBO9780511791222

Cohen, A.D., \& Olshtain, E. (1983). E.(1981) Developing a measure of sociocultural competence: The case of apology. Language Learning, 31, 113-134. http://dx.doi.org/10.1111/j.1467-1770.1981.tb01375.x

Crystal, D. (2001). Language and the Internet: Cambridge University Press. http://dx.doi.org/10.1017/CBO9781139164771

Ellis, Rod. (1997). Second language acquisition (Vol. 2): Oxford University Press.

Eslami-Rasekh, A, \& Mardani, Mehdi. (2010). Investigating the effects of teaching apology speech act, with a focus on intensifying strategies, on pragmatic development of EFL learners: The Iranian context. The International Journal of Language Society and Culture, 30, 97-103.

Hussein, R.F., \& Hammouri, M.T. (1998). Strategies of apology in Jordanian Arabic And American English. Grazer Linguistische Studien(49), 37-50.

İstifçi, İlknur. (2009). The use of apologies by EFL learners. Editorial Board, 15.

Manes, J., \& Wolfson, N. (1981). The compliment formula. Conversational routine: Explorations in standardized communication situations and prepatterned speech, 115-132.

Mustaffa, Normah, Ibrahim, Faridah, Mahmud, Wan Amizah Wan, Ahmad, Fauziah, Kee, Chang Peng, \& Mahbob, Maizatul Haizan. (2011). Diffusion of Innovations: The Adoption of Facebook among Youth in Malaysia. The Public Sector Innovation Journal,, 16(3), 1-15.

Pütz, Martin, \& Neff-van Aertselaer, JoAnne. (2008). Developing contrastive pragmatics: Interlanguage and cross-cultural perspectives (Vol. 31): De Gruyter Mouton.

Thijittang, Siriruck, \& Lê, Thao. (2010). Pragmatics Strategies of English of Thai University Students. Paper presented at the AARE.

Trosborg, A. (1994). Requests, Complaints andApologies: NewYork: Mouton deGruyter.

Wilson, R.E., Gosling, S.D., \& Graham, L.T. (2012). A review of Facebook research in the social sciences. Perspectives on Psychological Science, 7(3), 203-220. http://dx.doi.org/10.1177/1745691612442904 
APPENDDIX A

ENGLISH VERSION OF THE QUESTIONNAIRE

Apology Instrument

\section{Instructions}

Dear respondents

I am carrying out a study entitled 'Apology Strategies of Jordanian EFL Postgraduate Students with Implication for Interlanguage Pragmatics'. There are eight brief situations calling for an apology. Kindly respond to the situations as natural as possible as you would in an actual situation. Be assured that the information obtained in the course of this study will be kept confidential and used only for the purposes of academic research.

Thank you

Ala'EddinBanikalef

I. GENERAL INFORMATION

Name

Age:

Educational Level:

II. Please respond to these questions as realistically and honestly as possible.

\section{Situation 1}

You are a university professor and you promised to return the student's term paper that day but didn't finish reading it.

- (Student: "I hope you are happy with it. ")

- You:

\section{Situation 2}

You are a student and you borrowed your professor's book, which you promised to return that day, but forget to bring it.

- (Professor: "Have you brought the book?")

- You:

\section{Situation 3}

You completely forget a crucial meeting at the office with your boss. An hour later you call him to apologize. The problem is that this is the second time you have forgotten such a meeting. Your boss gets in the line and asks:

- (Boss: 'What happened to you?')

- You:

\section{Situation 4}

You forget a get-together with a friend. You call him to apologize. This is already second times you have forgotten such a meeting. Your friend asks over the phone:

- (Friend: 'What happened"?)

- You:

\section{Situation 5}

You call from work to find out how things are at home and your kid reminds you that you forget to take him shopping, as you had promised. And this is the second time that this has happened, your kid says over the phone:

- (Kid: “Oh, you forget again and you promised!”)

- You: 


\section{Situation 6}

Backing out of parking place, you run into the side of another car. It was clearly your fault. You dent in the side door slightly. The driver gets out and comes over to you angrily.

- (Driver. "Can't you look where you are going? See what you have done?”)

- You:

\section{Situation 7}

At an expensive restaurant and after the waitress has brought your order, you change your mind. You want to apologize and change the order.

- (The waitress: "But this is what you have already ordered!")

- You:

\section{Situation 8}

You are at a meeting and you say something that one of the participants interprets as a personal insult to him.

- (He: "I feel that your last remark was directed at me and I take offense.")

- you: 